\title{
Detection of icaA, icaD genes and biofilm production by Staphylococcus aureus and Staphylococcus epidermidis isolated from urinary tract catheterized patients
}

\author{
Gamal Fadl Mahmoud Gad ${ }^{3}$, Mohamed Ali El-Feky ${ }^{1}$, Mostafa Said El-Rehewy ${ }^{1}$, Mona Amin \\ Hassan1, Hassan Abolella ${ }^{2}$, and Rehab Mahmoud Abd El-Baky ${ }^{3}$ \\ ${ }^{1}$ Microbiology Department, Faculty of Medicine, Assuit University, Assuit, Egypt \\ ${ }^{2}$ Urology Department, Faculty of Medicine, Assuit University, Assuit, Egypt \\ ${ }^{3}$ Microbiology Department, Faculty of Pharmacy, El-Minia University, El-Minia, Egypt
}

\begin{abstract}
Background: Staphylococci are a common cause of catheter-associated urinary tract infections. The present study evaluated biofilm forming capacity and the presence of both icaA and icaD genes among staphylococci strains isolated from patients undergoing ureteral catheterization.

Methodology: Different bacterial strains were isolated from urine and stents segments collected from 100 patients. Strains were identified by traditional microbiological methods. Stents were examined for biofilm using a scanning electron microscope (SEM). Staphylococcal isolates were tested for their ability to produce biofilm using the tissue culture plate assay method (TCP). The presence of $i c a A$ and $i c a D$ genes was determined by PCR technique.

Results: Fifty-three staphylococcal strains were isolated and identified from 284 samples (18.7\%). Forty-six staphylococcal strains were isolated from stent segment cultures while only seven strains were isolated from urine samples at the day of stent removal. S. aureus represented 6.3\%, and S. epidermidis represented 12.3\%. Out of the 18 S. aureus strains, 15 (83.3\%) were biofilm producers and out of 35 S. epidermidis strains, $31(88.6 \%)$ were biofilm producers. Staphylococcal strains were further classified as high $(56.6 \%)$, moderate $(30.2 \%)$ and non biofilm producers (13.2\%). All biofilm producing strains were positive for icaA and icaD genes, and all biofilm negative strains were negative for both genes.

Conclusion: Staphylococci isolated from catheter segments showed a higher extent of biofilm production than that isolated from urine samples. All biofilm producing staphylococci were positive for icaA and icaD genes, which indicates the important role of ica genes as virulence markers in staphylococcal infections associated with urinary catheterization.
\end{abstract}

Keywords: Staphylococci, biofilm, icaA, icaD

J Infect Dev Ctries 2009; 3(5):342-351.

Received 26 December 2008 - Accepted 15 March 2009

Copyright $\odot 2009 \mathrm{Gad}$ et al. This is an open access article distributed under the Creative Commons Attribution License, which permits unrestricted use, distribution, and reproduction in any medium, provided the original work is properly cited.

\section{Introduction}

Staphylococci are most often associated with chronic infection of implanted medical devices. The increased use of indwelling medical devices has had considerable impact on the role of staphylococci in clinical medicine. The predominant species isolated in these infections are Staphylococcus epidermidis and Staphylococcus aureus. It was found that the major pathogenic factor is the ability to form biofilm on polymeric surfaces to which it adheres and colonizes artificial materials [1]. Biofilms are a population of multilayered cells growing on a surface and enclosed in exopolysaccharide matrix. Biofilm formations are considered to be a two-step process in which the bacteria first adhere to a surface, followed by multiplication to form a multilayered biofilm.
Microbial biofilms are considered the major problem posed to catheterized patients because they cause chronic infections which are difficult to treat, lead to longer hospitalization time, and can result in much higher treatment costs [2]. Biofilm formation is regulated by expression of polysaccharide intracellular adhesion (PIA), which mediates cell to cell adhesion and is the gene product of icaADBC [3]. The intercellular adhesion (ica) locus consisting of the genes icaADBC encodes proteins mediating the synthesis of PIA and polysaccharide/adhesin PS/A in staphylococci species [4].

Among ica genes, icaA and icaD have been reported to play a significant role in biofilm formation in S. aureus and S. epidermidis [5]. The icaA gene encodes $\mathrm{N}$-acetylglucosaminyltransferase, 
the enzyme involved in the synthesis of $\mathrm{N}$ acetylglucosamine oligomers from UDP-Nacetylglucosamine. Further, icaD has been reported to play a role in the maximal expression of $\mathrm{N}$ acetylglucosaminyltransferase, leading to the phenotypic expression of the capsular polysaccharide [6]. The aim of our study was to determine the biofilm-forming capacity of microorganisms isolated from urinary tract catheterized patients and the occurrence of icaA and icaD genes in biofilmproducing strains in a collection of staphylococcal isolates.

\section{Materials and methods}

Patients, specimens, and strains

Patients

Our institution did not require informed consent from patients. All patients were selected by Dr. Hassan Abolella (Professor of Urology, Department of Urology at Assuit University Hospital) during the study period from December 2007 to June 2008. However, all samples were collected after we obtained informed consent from each patient, following a discussion with each about our study in order to facilitate our work. Eight patients of our study did not return to undergo stent removal in the hospital. This was the reason that the number of urine samples and stent segment was 92 instead of 100 on the day of stent removal.

\section{Specimens}

Two hundred and eighty four clinical samples (urine samples and stent segments) were collected from 100 in-patients undergoing ureteral catheterization at the Department of Urology at Assuit University Hospital. One hundred urine samples were collected from patients before stent insertion and 92 urine samples were collected at the day of stent removal. Ninety-two catheter segments were collected from the 92 patients undergoing ureteral stent removal. Urine samples were streaked onto the surfaces of mannitol salt agar, MacConkey agar, and blood agar and incubated at $37^{\circ} \mathrm{C}$ for 24 hours [7]. Each catheter sample was placed in $10 \mathrm{ml}$ of trypticase soy broth (TSB, Difco), sonicated for one minute, and then vortexed for 15 seconds. Exactly $0.1 \mathrm{ml}$ of the sonicated broth was surfaceplated by using a wire loop on trypticase soy agar (TSA) (with 5\% sheep blood) and MacConkey agar. Organisms were then identified by routine microbiological techniques [8], and API Staph system (Biomerieux, France) was used to screen all coagulase negative staphylococci, following the instructions of the manufacturer. Different biochemical activities were performed for identification of the isolated strains according to the standard biochemical methods described by Koneman et al. (9) and Collee et al. (10).

\section{Strains}

In the present study, 292 strains were recovered and identified from 284 clinical samples. Out of 292 isolates, 53 were staphylococci, which were used in our study. The organisms were stored in trypticase soy broth (TSB), to which $15 \%$ glycerol was added at $-20^{\circ} \mathrm{C}$.

\section{Scanning Electron Microscopy (SEM)}

Catheter segments were fixed in $2.5 \%$ ( $\mathrm{vol} / \mathrm{vol})$ glutaraldehyde in Dulbecco PBS (PH 7.2) for 1.5 hours, rinsed with PBS, and then dehydrated through an ethanol series. Samples were dried and goldpalladium coated. SEM examinations were made on a JSM-840 SEM (JEOL Ltd., Tokyo, Japan) [11].

\section{Detection of biofilm formation by tissue culture plate method (TCP)}

The TCP assay is most widely used and was considered as standard test for detection of biofilm formation. All isolates were screened for their ability to form biofilm by the TCP method as described by Christensen et al. [12] with a modification in duration of incubation which was extended to 24 hours, according to O'Toole and Kolter [13].

Isolates from fresh agar plates were inoculated in trypticase soy broth with $1 \%$ glucose and incubated for 24 hours at $37^{\circ} \mathrm{C}$ in stationary condition and diluted (1 in 100) with fresh medium. Individual wells of sterile, polystyrene, flat-bottom tissue culture plates were filled with $0.2 \mathrm{ml}$ aliquots of the diluted cultures, and only broth served as control to check sterility and non-specific binding of media.

The tissue culture plates were incubated for 24 hours at $37^{\circ} \mathrm{C}$. After incubation, the content of each well was gently removed by tapping the plates. The wells were washed four times with $0.2 \mathrm{ml}$ of phosphate buffer saline (PBS $\mathrm{pH}$ 7.2) to remove freefloating planktonic bacteria; then $25 \mu$ of $1 \%$ solution of crystal violet was added to each well (this dye stains the cells but not the polystyrene) plates. The plates were incubated at room temperature for 15 minutes, rinsed thoroughly and repeatedly with water. Adherent cells, which usually formed biofilm 
on all side wells, were uniformly stained with crystal violet. Crystal violet-stained biofilm was solubilized in $200 \mu \mathrm{l}$ of $95 \%$ ethanol (to extract the violet color), of which $125 \mu \mathrm{l}$ were transferred to a new polystyrene microtiter dish, which was then read. Optical densities (OD) of stained adherent bacteria were determined with a micro ELISA auto reader (model 680, Bio rad), and the wavelength of values was considered as an index of bacteria adhering to surface and forming biofilms. Experiments for each strain were performed in triplicate and repeated three times. To compensate for background absorbance, OD readings of wells with ethanol were used as blank and subtracted from all tests' values. Biofilm production is considered high, moderate, or weak 570 $\mathrm{nm}\left(\mathrm{OD}_{570 \mathrm{~nm}}\right)$ as shown in Table 1.

Table 1. Classification of bacterial adherence by TCP method.

\begin{tabular}{|l|l|l|}
\hline Biofilm formation & Adherence & Mean OD values \\
\hline Non/weak & Non/weak & $<0.120$ \\
\hline Moderate & Moderately & $0.120-0.240$ \\
\hline High & Strong & $>0.240$ \\
\hline
\end{tabular}

\section{PCR for amplification of icaA and icaD sequences}

Bacterial DNA extraction

After overnight culture on brain-heart infusion agar plates, one or two colonies were suspended in 20 $\mathrm{ml}$ of sterile distilled water, and the suspension was then heated at $100^{\circ} \mathrm{C}$ for 20 minutes. From this suspension, a $5 \mu \mathrm{l}$ aliquot was directly used as a template for PCR amplification.

The sequences of icaA and icaD were taken from the GenBank sequence database of the National Center for Biotechnology Information. Primers specific for icaA and icaD were picked on the gene sequences by the Primer3 program. The primers were synthesized by Koma Biotech Inc. (Kore).

For the detection of icaA, 5'TCTCTTGCAGGAGCAATCAA was used as a forward primer and 5'TCAGGCACTAACATCCAGCA was used as a reverse primer. The two primers include a 188 -bp region. For detection of icaD, 5'ATGGTCAAGCCCAGACAGAG was used as a forward primer and 5'CGTGTTTTCAACATTTAATGCAA was used as a reverse primer. The two primers include a 198-bp region. PCR was performed in a DNA thermal cycler (UNO II Thermocycler; Biometra GmbH, Gottingen, Germany). The reaction volume was $25 \mu$ containing
$2.5 \mu \mathrm{L}$ of each the forward and reverse primers (1 $\mu \mathrm{M}$ each), together with $150 \mathrm{ng}(5 \mu \mathrm{l})$ of the extracted DNA, $10 \mu \mathrm{l}$ of EzWay ${ }^{\mathrm{TM}}$ PCR Master Mix and $5 \mu \mathrm{l}$ of distilled water.

A thermal step program for both icaA and icaD was used, including the following parameters: incubation at $94^{\circ} \mathrm{C}$ for 5 minutes, followed by 50 cycles at $94^{\circ} \mathrm{C}$ for 30 seconds (denaturation), $55.5^{\circ} \mathrm{C}$ for 30 seconds (annealing), $72^{\circ} \mathrm{C}$ for 30 seconds (extension), and $72^{\circ} \mathrm{C}$ for 1 minute after conclusion of the 50 cycles. After the first 30 cycles, a further 1 $\mathrm{U}$ of Taq DNA polymerase was added. After amplification, $10 \mu \mathrm{l}$ of the PCR mixture was analyzed by agarose gel electrophoresis (2\% agarose in Trisborate-EDTA stained with ethidium bromide). The Gene Ruler 100 bp DNA ladder (Koma Biotech Inc., Kore) was used as a DNA size marker [6].

\section{Results}

Seventy-six patients $(76 \%)$ before stent insertion and 80 patients $(86.95 \%)$ on the day of stent removal had positive urine cultures, and $84(91.3 \%)$ patients had positive stent cultures.

A total of 292 bacterial isolates were recovered from 284 clinical samples collected from 100 patients. As shown in Table 2, Klebseilla spp. were the most prevalent microorganism $(21.9 \%)$ followed by Pseudomonas spp. (18.8\%) and Staphylococci spp. (18.2\%). Out of 292 isolates, 53 staphylococcal strains were identified (18.2\%). Staphylococcus aureus represented $6.2 \% \quad(18$ strains $)$ and Staphylococcus epidermidis represented $12 \%$ (35 strains).

Table 2. Prevalence of different microorganisms isolated from different patients.

\begin{tabular}{|l|c|c|}
\hline Microorganisms & No. & \%* \\
\hline Staphylococci spp.: & $\underline{53}$ & 18.2 \\
S. aureus & 18 & 6.2 \\
S. epidermidis & 35 & 12 \\
\hline E. coli & 52 & 17.8 \\
\hline Klebseilla spp.: & $\underline{64}$ & 21.9 \\
\hline K. pneumoniae & 40 & 13.7 \\
K. oxytocae & 24 & 8.2 \\
\hline Pseudomonas spp. & 55 & 18.8 \\
\hline Proteus spp. & $\underline{33}$ & 11.3 \\
\hline p. vulgaris & 17 & 5.8 \\
p. mirabilis & 16 & 5.5 \\
\hline Provedencia rettgeri & 14 & 4.8 \\
\hline Citrobacter freundii & 14 & 4.8 \\
\hline Serratia marcescens & 7 & 2.4 \\
\hline *Percents were correlated to the tota & &
\end{tabular}


Polymicrobial bacteriuria represented $22.9 \%$ of positive cultures. All staphylococcal strains were polymicrobial with klebseilla pneumoniae, E. coli, Pseudomonas spp., Proteus spp., Providencia rettgeri, and Serratia marcescens. For S. aureus, five strains were found mixed with $K$. pneumoniae, six strains with Pseudomonas spp., four strains with Proteus spp., one strain with Providencia rettgeri, and two strains with Serratia marcescens. For $S$. epidermidis, seven strains were found mixed with $E$. coli, 10 strains with $K$. pneumoniae, 12 strains with Pseudomonas spp., three strains with Proteus spp. and three strains with Serratia marcescens.

\section{Detection of biofilm producing strains}

Stents examined by scanning electron microscope showed two types of bacteria, a dense mass of biofilm, and a high level of encrustation (Figure 1). To explain the presence of biofilm mass and encrustation, biofilm producing ability was tested by TCP method for all isolates (Table 3). Table 3 shows that most of isolates were biofilm producers, which explains the presence of a dense mass of biofilm produced by two microorganisms on both the surface and the lumen of the catheter. Urease enzyme production was tested for all isolates. It was found that most of isolates were urease positive, which increased urine $\mathrm{pH}$ and produced an alkaline condition resulting in precipitation of $\mathrm{Ca}$ and Magnesium phosphate (Table 4). isolates among different samples. All staphylococcal strains were isolated from urine samples on the day of stent removal (three strains of $S$. aureus and four strains of $S$. epidermidis) and stent segments (15 strains of $S$. aureus and 31 strains of $S$. epidermidis). Staphylococci were not isolated from urine samples before stent insertion. In addition, staphylococci were isolated from stent segments cultures in an incidence higher than that from urine samples on the day of stent removal. Table 5 also shows that staphylococci were not isolated from the urine sample and catheter segment of the same patient, which indicates that the sensitivity of urine cultures to stent colonization is low, and negative urine cultures do not rule out a colonized stent.

Staphylococcal strains of different origin were further classified according to the extent of biofilm production to high, moderate and non/weak biofilm producers. $S$. aureus and $S$. epidermidis strains isolated from urine samples were non/weak biofilm producers, but those isolated from catheter segments were moderate and high biofilm producers. Out of eighteen $S$. aureus isolates, twelve $(66.7 \%)$ were strong biofilm producers, three $(16.7 \%)$ were moderate biofilm producers, and three $(16.7 \%)$ were considered as non or weak biofilm producers. On the other hand, out of 35 S. epidermidis, 18 (51.4\%) were strong biofilm producers, 13

Table 3. The incidence of biofilm production among the isolated microorganisms using microtiter plate method.

\begin{tabular}{|l|c|c|c|}
\hline Microorganisms & No. of microorganisms & \multicolumn{2}{|c|}{ Number of biofilm producing organisms } \\
\cline { 3 - 4 } & & No. & \%* \\
\hline S. aureus & 18 & 15 & 83.3 \\
\hline S. epidermidis & 35 & 31 & 88.6 \\
\hline E. coli & 52 & 40 & 76.9 \\
\hline Klebseilla spp. & 64 & 54 & 84.8 \\
\hline Pseudomonas spp. & 55 & 50 & 90.9 \\
\hline Proteus spp. & 33 & 28 & 84.4 \\
\hline Provedencia rettgeri & 14 & 12 & 85.7 \\
\hline Citrbacter freundii & 14 & 12 & 85.7 \\
\hline serratia marcescens & 7 & 5 & 71.4 \\
\hline Total & 292 & 247 & 84.6 \\
\hline
\end{tabular}

*Percents were correlated to the number of each isolate.

A higher incidence of Staphylococci was isolated from catheter segments than from urine samples. Table 5 shows the distribution of staphylococcal
(37.1\%) were moderate biofilm producers, and four $(11.4 \%)$ were considered as weak or non biofilm producers (Table 6 and Figure 2). 
Table 4. Incidence of urease enzyme production by biofilm producing microorganisms.

\begin{tabular}{|l|c|c|c|}
\hline \multirow{2}{*}{ Microorganisms } & $\begin{array}{l}\text { No. of microorganisms } \\
\text { producing biofilm }\end{array}$ & \multicolumn{2}{|c|}{ No. of urease positive organisms } \\
\cline { 2 - 4 } & & No. & $\% *$ \\
\hline Staphylococci: & $\frac{46}{15}$ & $\frac{7}{15.2}$ & 26.7 \\
S. aureus & 31 & 3 & 9.7 \\
S. epidermidis & 40 & 0 & 0 \\
\hline E.coli & 54 & 23 & 42.9 \\
\hline Klebseilla Spp. & 28 & 26 & 92.9 \\
\hline Proteus Spp. & 50 & 39 & 78 \\
\hline Pseudomonas Spp. & 12 & 6 & 50 \\
\hline Providencia rettgeri & 12 & 5 & 41.7 \\
\hline Citrbacter freundii & 5 & 109 & 64.12 \\
\hline Serratia marcescens & 247 & & \\
\hline Total & & & \\
\hline
\end{tabular}

Table 5. Distribution of staphylococcal strains isolated from different urine samples and stent segments.

\begin{tabular}{|l|c|c|c|c|}
\hline Samples & \multicolumn{2}{|l|}{ S. aureus $(\mathbf{n = 1 8})$} & \multicolumn{2}{l|}{ S. epidermidis $(\mathbf{n = 3 5})$} \\
\cline { 2 - 5 } & No. & $\%$ & No. & $\%$ \\
\hline Urine samples before stent insertion & 0 & 0 & 0 & 0 \\
\hline Urine samples at the day of stent removal only & 3 & 16.7 & 4 & 11.4 \\
\hline Catheter segment only & 15 & 83.3 & 31 & 88.6 \\
\hline Urine sample and stent segment of the same patient & 0 & 0 & 0 & 0 \\
\hline
\end{tabular}

Table 6. Screening of the extent of biofilm formation by the isolated staphylococci by tissue culture plate assay (TCP).

\begin{tabular}{|c|c|c|c|c|c|c|c|}
\hline \multirow{3}{*}{ Microorganism } & \multirow{3}{*}{$\begin{array}{l}\text { Number of } \\
\text { isolates }\end{array}$} & \multicolumn{6}{|c|}{ Biofilm formation $\left(\mathrm{OD}_{570 \mathrm{~nm}}\right)$} \\
\hline & & \multicolumn{2}{|c|}{ High } & \multicolumn{2}{|c|}{ moderate } & \multicolumn{2}{|c|}{ Non/weak } \\
\hline & & No. & $\% *$ & No. & $\% *$ & No. & $\% *$ \\
\hline S. aureus & 18 & 12 & 66.7 & 3 & 16.7 & 3 & 16.7 \\
\hline S. epidermidis & 35 & 18 & 51.4 & 13 & 37.1 & 4 & 11.4 \\
\hline
\end{tabular}

\section{PCR detection of icaA and icaD genes}

All strains were tested for the presence of icaA and $i c a D$ genes. All biofilm producing strains isolated from catheter segments were found to be positive for both genes, giving a 188-bp band for icaA, and a 198bp band for icaD genes. It was also found that all strains which were positive for icaA were also positive for icaD. On the other hand, all non biofilm producing strains isolated from urine samples were negative for both genes. The expression of icaA and icaD genes in strains isolated from catheter segments collected from patients indicates the role of ica genes in biofilm production and as virulence markers in staphylococcal infections associated with urinary tract catheters (Table 7 and Figure 3).

\section{Discussion}

Bacterial adhesion has long been considered as a virulence factor contributing to infections associated with catheters and other indwelling medical devices [14]. There are two possible explanations for the 
Figure 1A. Scanning electron micrograph showing the surface of a ureteral stent covered with a dense mass of biofilmcontaining bacteria $(S$. aureus $)$ and crystalline layers $(\times 5000)$.

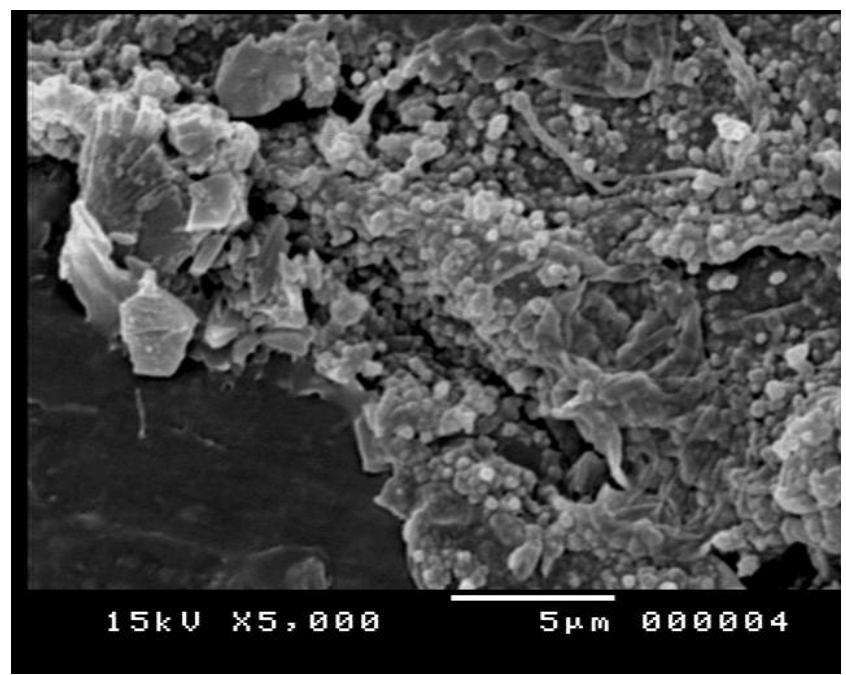

Figure 1C. Scanning electron micrograph showing the lumen of a ureteral stent covered with a big mass of biofilm-containing rods and cocci $(K$. pneumoniae and $S$. aureus $)(\times 5000)$.

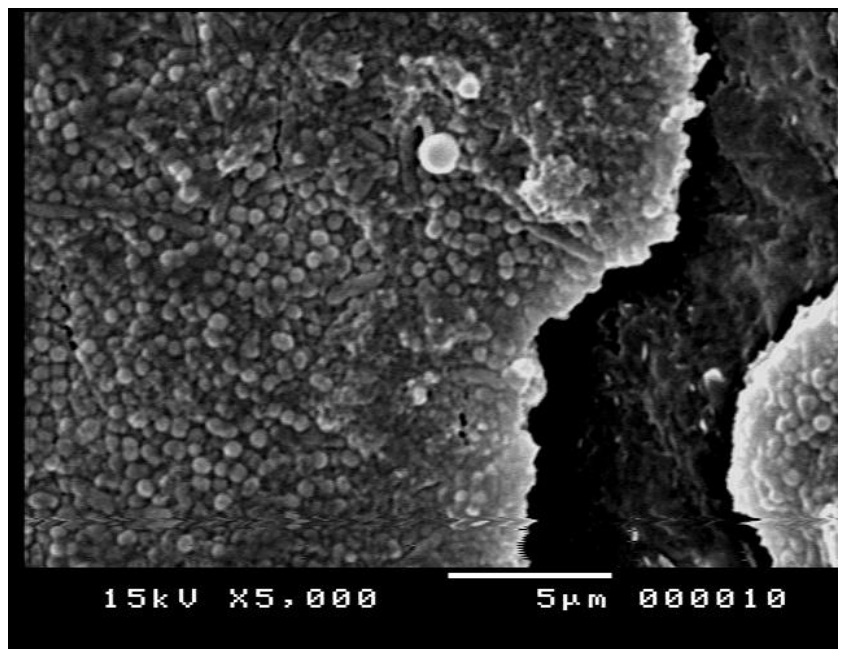

Figure 1B. Scanning electron micrograph showing the surface of a ureteral stent covered with high dense crystalline biofilm $(\times 5000)$.

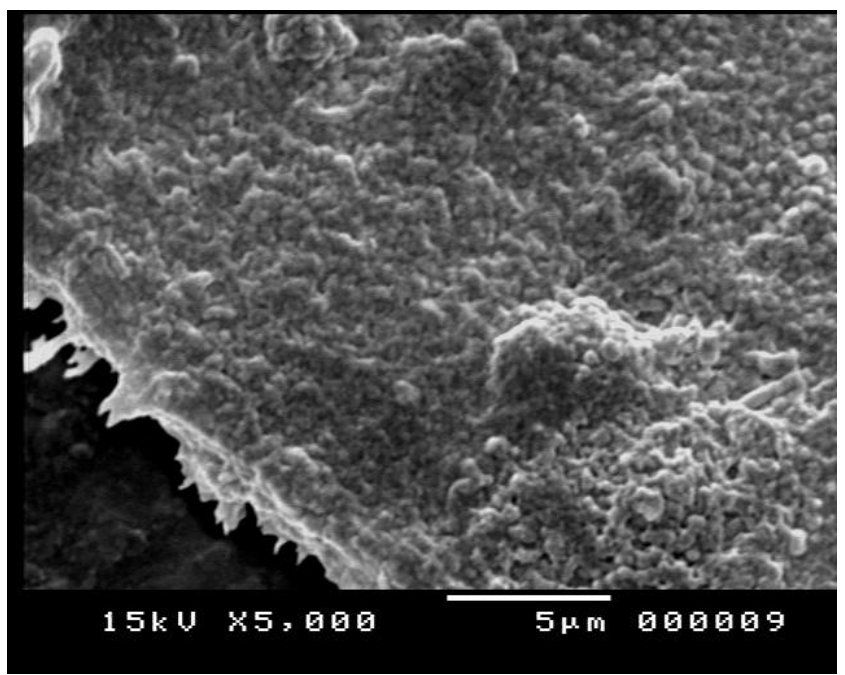

Figure 1D. Scanning electron micrograph showed the lumen of the ureteral stent $(\times 35)$ blocked with a dense mass of biofilm.

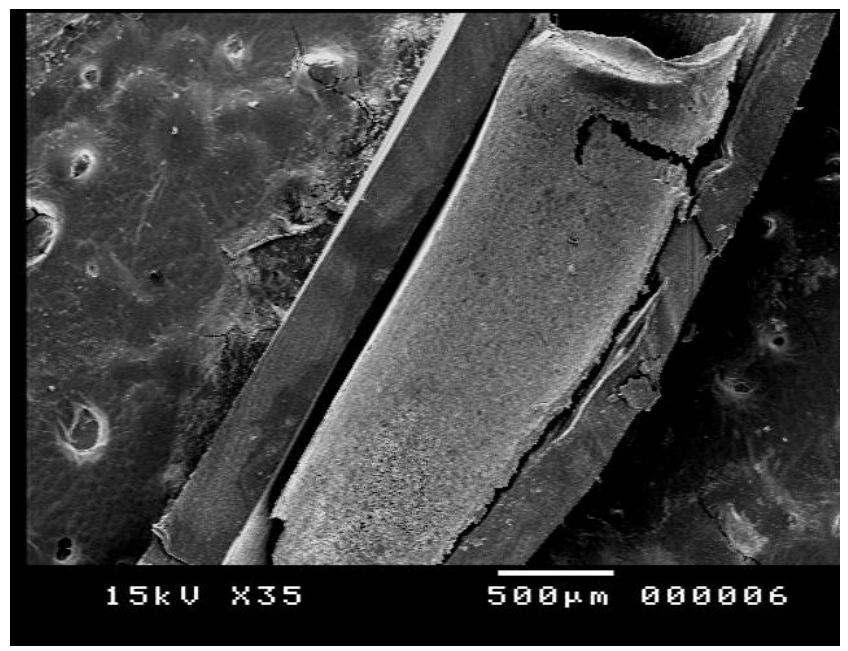

Figure 2. Screening of biofilm producers by Tissue culture plate method (TCP): high, moderate and weak/non biofilm producers.
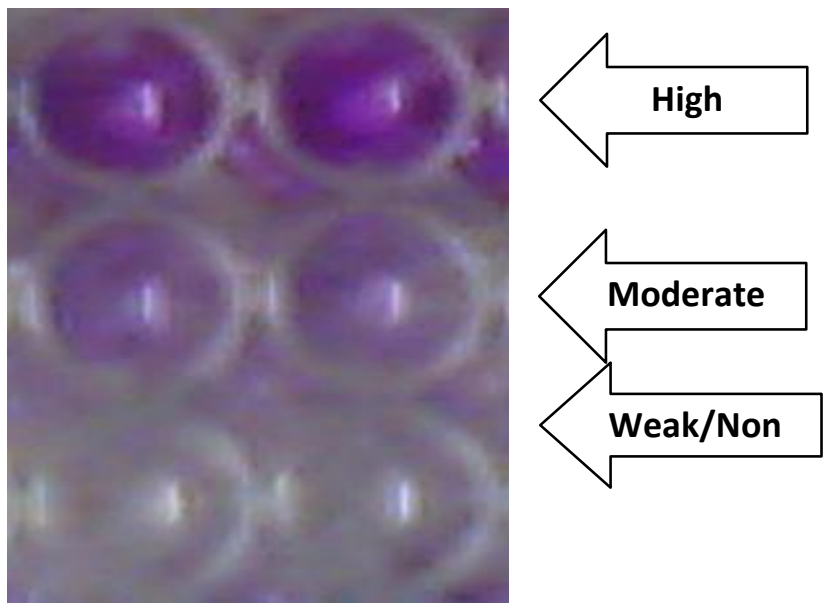
Table 7. Relationships among biofilm production (TCP assay), the presence of $i c a A$ and $i c a D$ genes and sample origin.

\begin{tabular}{|c|c|c|c|c|c|c|c|c|}
\hline \multirow[t]{3}{*}{ Microorganisms } & \multicolumn{4}{|c|}{ Number of biofilm positive strains } & \multirow{2}{*}{\multicolumn{2}{|c|}{$\begin{array}{c}\text { Total } \\
\text { positive }\end{array}$}} & \multirow{2}{*}{\multicolumn{2}{|c|}{$\begin{array}{c}\text { Strains positive } \\
\text { for icaA and } \\
\text { icaD }\end{array}$}} \\
\hline & \multicolumn{2}{|c|}{ Catheter segments } & \multicolumn{2}{|c|}{$\begin{array}{l}\text { Urine samples at } \\
\text { the day of stent } \\
\text { removal }\end{array}$} & & & & \\
\hline & No. & \%* & No. & \%* & No. & \%* & No. & \%* \\
\hline S. aureus $(\mathrm{n}=18)$ & 15 & 83.3 & 0 & 0 & 15 & 83.3 & 15 & 83.3 \\
\hline S. epidermidis $(n=35)$ & 31 & 88.6 & 0 & 0 & 31 & 88.6 & 31 & 88.6 \\
\hline Total $(n=53)$ & 46 & 86.8 & 0 & 0 & 46 & 86.8 & 46 & 86.8 \\
\hline
\end{tabular}

Figure 3. PCR detection of icaA and icaD genes in 4 Staphylococcus aureus strains ( 1 and 3 were biofilm producers and 2 and 4 were non-biofilm producers).

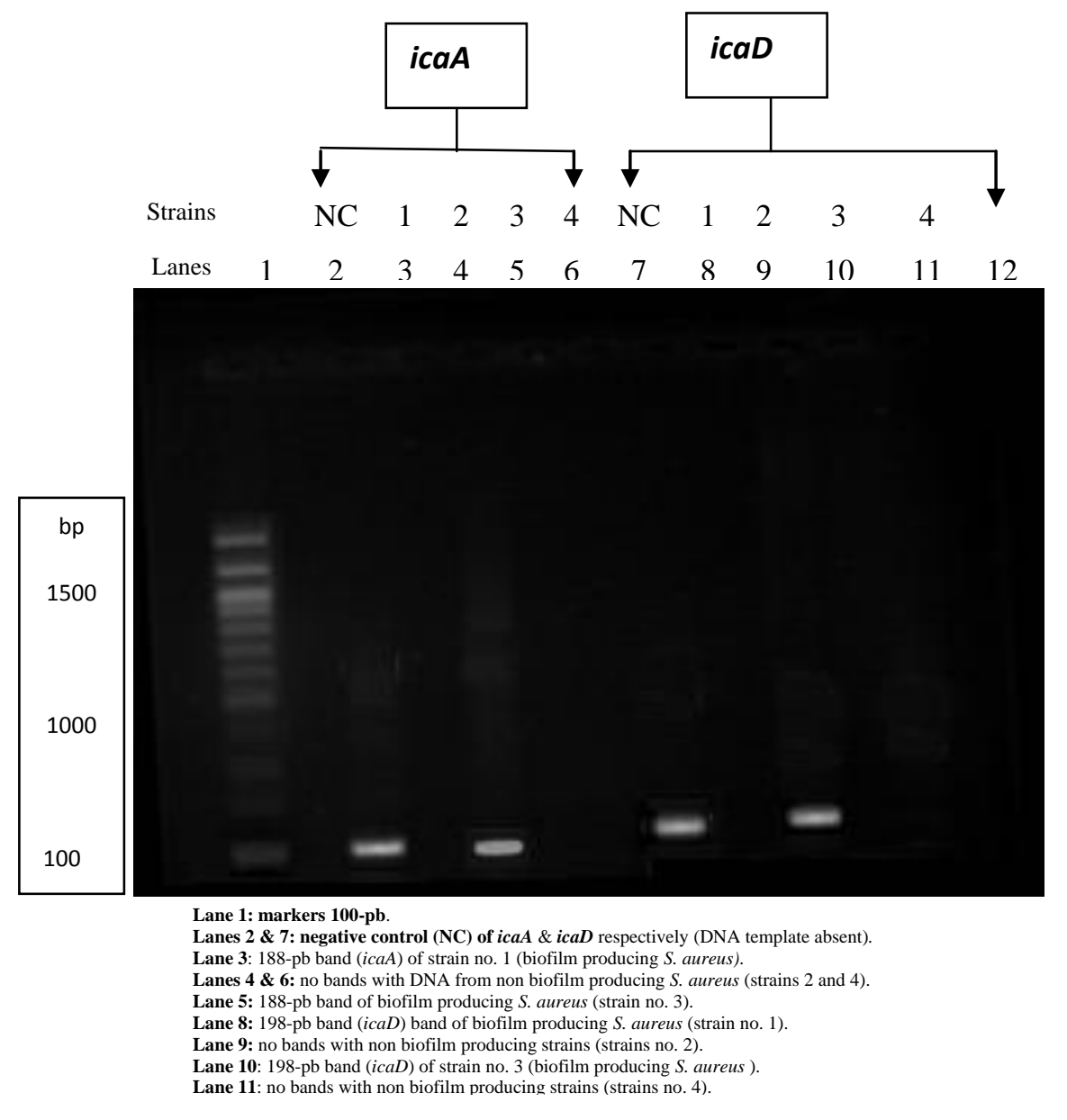


ability of staphylococcal species to colonize artificial materials. The first is the bacterial production of polysaccharide slime. The second is the presence of adhesins for the host matrix proteins that are adsorbed onto the biomaterial surface [15]. The ability of staphylococci to form biofilms helps the bacterium to resist host immune response and is considered responsible for chronic or persistent infections as biofilm protects microorganisms from opsonophagocytosis and antimicrobial agents [16, 17].

In this study, it was found that Klebseilla spp. was the most prevalent microorganism (21.9\%), followed by Pseudomonas spp. (18.8\%), staphylococci spp. (18.2\%) and E. coli (17.8\%). These results are close to those obtained by Reid et al. [18], who reported that Klebseilla species were the most prevalent microorganism $(33.3 \%)$ isolated from 42 hospitalized patients with urinary tract catheters, followed by E. coli $(26.2 \%)$, and coagulase negative staphylococci (11.9\%). Similar results were obtained in a surveillance study carried out by Savas et al. [19] to determine microorganisms responsible for urinary tract infection (UTI), who found that Klebseilla spp. (21.9\%), E. coli (18.8\%), and Pseudomonas spp. (17.8\%) were the most prevalent microorganisms isolated from urinary tract catheterized patients. On the other hand, they found that coagulase negative staphylococci were isolated only from urine samples of non catheterized patients, which differs from our results. Our results showed that polymicrobial bacteriuria represented $21.9 \%$ of positive cultures, which are close to results obtained by Ko et al. [20], who reported that polymicrobial bacteriuria represented $21.1 \%$.

Scanning electron microscope (SEM) was used to examine catheters for the presence of encrustation and bacterial biofilm. Scanning electron micrographs showed biofilm mass formed on the surface and the lumen of the catheters containing two types of microorganisms. The surface of catheters showed high levels of encrustation, which may be due to urease production by the existing microorganisms, which increases urine $\mathrm{pH}$ resulting in calcium and magnesium phosphate precipitation. Many researchers used SEM to examine urinary catheters for crystalline biofilms [21-24].

Our findings indicate that the sensitivity of urine cultures to stent colonization is low, which supports results obtained by Kehinde et al. [25], who found that on the day of stent removal, $17 \%$ of patients had positive urine cultures, while $42 \%$ of stents cultures were positive.

Christensen et al. [12] reported that optical densities of bacterial biofilms adherent to plastic tissue culture plates (TCP) serve as a quantitative model for the study of the adherence of coagulase negative staphylococci to medical devices and act as a reliable quantitative tool for comparing the adherence of different strains. They also found that classifying strains into three adherence groups indicated the distance between the adherence coordinates and the origin. Furthermore, they found that coagulase negative staphylococci isolated from catheters associated with sepsis were found to be more strongly adherent than those isolated from blood culture contaminant and skin strains, which agrees with our results as strains isolated from catheters were more strongly adherent than those isolated from urine samples. Mathur et al. [26] reported also that the TCP method is an accurate and reproducible method for screening and determination of biofilm production. Therefore, we used this method in our study. Mather's group also showed that increasing the incubation period from 18 hours to 24 hours could lead to a better discrimination between moderate and non biofilm producing staphylococci. Under conditions of using TSB media supplemented with $1 \%$ glucose and an 18-hour incubation period, 80 staphylococci strains showed biofilm production, but after a 24-hour incubation period, the number of biofilm producing strains increased to 82. In our study, we used the same conditions (TSB with $1 \%$ glucose and a $24 \mathrm{~h}$ incubation period) since the use of sugar supplementations is essential for biofilm formation and since extended incubation time affects biofilm formation in staphylococci.

In the present study, all biofilm and non biofilm producing staphylococci strains ( $S$. aureus and $S$. epidermidis) were subjected to PCR for determining $i c a A$ and icaD genes to identify and confirm biofilm producing strains. It was found that all biofilm producing staphylococci strains were positive for $i c a A$ and $i c a D$ genes. These results are in agreement with those of De Silva et al. [27] and Mack et al. [28]. Arciola et al. [6] reported that all S. aureus and $S$. epidermdis biofilm positive strains isolated from intravenous catheters were positive for icaA and icaD genes and that these genes are required for full slime synthesis, which is in agreement with our results. These findings are consistent with those of other studies that showed a high incidence of slime 
producing staphylococci in isolates from clinically significant medical device-associated infections of different origins [29-33].

Biofilm production is an important pathogenic factor which facilitates adherence of microorganisms to medical devices and protects them from the host immune system and antimicrobial therapy. Results revealed that both $i c a A$ and $i c a D$ genes were either present or absent and no single strain had shown the presence of one gene. These results confirm the fact that both genes are part of one operon and so the entire operon was either present or absent. In addition, our results showed that both genes (icaA and icaD) were present in all biofilm producing strains, indicating the important role of ica genes as virulence markers in staphylococcal infections. In conclusion, there is a high prevalence of biofilm production among microorganisms isolated from catheterized patients, the sensitivity of urine cultures to stent colonization is low, and staphylococci isolated from catheter segments showed a higher extent of biofilm production than those isolated from urine samples. All biofilm producing staphylococci were positive for $i c a A$ and $i c a D$ genes. It is important to diagnose and to give prophylactic antibiotics just before and during the surgical procedure to eliminate plankotonic bacteria before they can form a biofilm.

\section{References}

1. Kloos WE, and Bannerman TL (1994) Update on clinical significance of coagulase-negative Staphylococci. Clin Microbiol Rev 7: 117-40.

2. Desgrandchamps F, Moulinier F, Doudon M, Teillac P, Le Duc A. (1997) An in-vitro comparison of urease induced encrustation of JJ stents in human urine. Br J Urol 79: 247.

3. Ammendolia MG, Rosa RD, Montanaro L, Arciola CR and Baldassarri L (1999) Slime production and expression of slime-associated antigen by staphylococcal clinical isolates. J Clin Microbiol 37: 3235-8.

4. O'Gara J P, and Humphreys H. (2001) Staphylococcus epidermidis biofilms importance and implications. $\mathrm{H}$ Med Microbiol 50: 582-87.

5. Yazdani R, Oshaghi M, Havayi A, Salehi R, Sadeghizadeh M, Foroohesh H. (2006) Detection of icaAD gene and biofilm formation in Staphylococcus aureus isolates from wound infections. Iranian J Publ Health 35: 25-28.

6. Arciola CR, Baldassarri L, and Montanaro L. (2001) Presence of $i c a A$ and $i c a D$ genes and slime production in a collection of staphylococcal strains from catheterassociated infections. J Clin Microbiol 39: 2151-2156.

7. Benson HC. (2002) Microbiological Application: Laboratory manual in general microbiology, $11^{\text {th }}$ ed., McGram-Hill Higher Education, San Francisco. p. 168.

8. Sheretz RJ, Raad IL, Balani A (1990) Three-year experience with sonicated vascular catheter cultures in a clinical microbiology laboratory. J Clin Microbiol 28: 7682 .

9. Koneman EW, Allen SD, Janda WM, Schreckenberger PC, and Winn WC (1994) Introduction to diagnostic microbiology, J. B. Lippincott Company, USA.

10. Collee JG, Fraser AG, Marmion BP, and Simmons A. (1996) Tests for identification of bacteria. In: Makie \& McCartney practical medical microbiology, $14^{\text {th }}$ ed., Churchill Livingstone In., New York 131-149.

11. Soboh F, Khoury AE, Zamboni AC, Davidson D, and Mittelman MW (1995) Effects of ciprofloxacin and protamine sulfate combinations against catheter-associated Pseudomonas aeruginosa biofilms. Antimicrob Agents Chemother 39: 1281-1286.

12. Christensen GD, Simpson WA, Younger JA, Baddour LM, Barrett FF, Melton DM, Beachey EH (1985) Adherence of coagulase negative Staphylococci to plastic tissue cultures: a quantitative model for the adherence of staphylococci to medical devices. J Clin Microbiol 22: 996-1006.

13. O'Toole AG and Kolter R (1998) Initiation of biofilm formation in Pseudomonas fluorescence WCS365 proceeds via multiple, convergent signaling pathways: a genetic analysis. Molecular microbiology 28: 449.

14. Francois P, Vaudaux P, Foster TJ, and Lew DP (1996) Host-bacteria interactions in foreign body infections. Infect Control Hosp Epidemiol 17: 514-520.

15. Montanaro L, Arciola CR, Borsetti E, Brigotti M, and Baldassarri L (1998) A polymerase chain reaction (PCR) method for the identification of collagen adhesin gene (cna) in Staphylococcus-induced prosthesis infections. New Microbiol 21: 359-363.

16. Cramaton SE, Gerke C, and Gotz F (2001) In-vitro method to study staphylococcal biofilm formation. Methods enzymol 336: 239-55.

17. Serralta VW, Harrison-Belestra C, Cazzaniga AL, Davis SC, and Mertz PM (2001) Lifestyle of bacteria in wounds: Presence of bofilms? Wounds 13: 29-34.

18. Reid G, Poter P, Delaney G, Hsieh J, Nicosia S, and Hayes K (2000) Ofloxacin for the treatment of urinary tract infections and biofilms in spinal cord injury. Int $\mathbf{J}$ Antimicrob Agents 13: 305-307.

19. Savas L, Guvel S, Onlen Y, Savas N, and Duran N (2006) Nosocomial urinary tract Infections: Microorganisms, antibiotic Sensitivities and Risk Factors. West Indian Med J 55: 188-193.

20. Ko M, Liu C, Woung L, Lee W, Jeng H, Lu S, Chiang H, and Li C (2008) Species and antimicrobial resistance of uropathogens isolated from patients with urinary catheters. Tohoku J Exp Med 214: 311-319.

21. Jones BV, Young R, Mahenthiraligam E. and Stickler DJ (2004) Ultrastructure of Proteus mirabilis swarmer cell rafts and role of swarming in catheter-associated urinary tract infection. Infect Immun 72: 3941-3950.

22. Stickler DJ (2005) Urinary catheters: ideal sites for the development of biofilm communities. www.sgm.ac.uk/pubs/micro_today/pdf/020505.pdf. Microbiology Today, Feb: 22-25.

23. Sabubba NA, Mahenthiraligam E, and Stickler DJ (2003) Molecular epidemiology of Proteus mirabilis infections of the catheterized urinary tract. J Clin Microbiol 41: 49614965.

24. Stickler DJ, Young R, Jones G, Sabubba NA, and Morris NS (2003) Why are Foley catheters so vulnerable to 
encrustation and blockage by crystalline bacterial biofilm? Urol Res 31: 306-311.

25. Kehinde EO, Rotimi VO, Al-Hunayan A, Abdul-Halim H, Boland F and Al-Awadi KA (2004) Bacteriology of urinary tract infection associated with indwelling $\mathrm{J}$ ureteral stents. J Endourol 18: 891-896.

26. Mathur T, Singhal S, Khan S, Upadhyay DJ, Fatma T, Rattan A (2006) Detection of Biofilm Formation among the clinical isolates of staphylococci: an evaluation of three different screening methods. Indian J Med Microbiol 24: 25-9.

27. De Silva GD, Kanatazanou M, Massey RC, Wikinson AR, Day NP, and Peacock SJ (2002) The ica operon and biofilm production in coagulase negative staphylococci associated with carriage and disease in neonatal intensive care unit. J Clin Microbiol 40: 382-388.

28. Mack D, Rohde H, Dobinsky S, Riedewald J, Nedelmann M, Knobloch JK, Elsner HA, and Feucht HH (2000) Identification of three essential regulatory gene loci governing expression of the Staphylococcus epidermidis polysaccharide intercellular adhesin and biofilm formation. Infect Immun 68: 3799-3807.

29. Ziebuhr W, Heilmann C, Gotz F, Meyer P, Wilms K, Straube E, Hacker J (1997) Detection of the intercellular adhesion gene cluster (ica) and phase variation in Staphylococcus epidermidis blood culture strains and mucosal isolates. Infect Immun 65: 890-6.

30. Arciola CR, Campoccia D, Gamerini S, Donati ME, Baldassarri L, Montanaro L (2003) Occurrence of ica genes for slime synthesis in a collection of Staphylococcus epidermidis strains from orthopedic prosthesis infections. Acta orthop Scand 74: 617-621.

31. Satorres SE, and Alcaráz LE (2007) Prevalence of icaA and icaD genes in Staphylococcus aureus and Staphylococcus epidermidis strains isolated from patients and hospital staff. Cent Eur J Pulic Health 15: 87-90.

32. Chaieb K, Zmantar T, Chehab O, Boucham O, Hasen AB, Mahdouani K, and Bakhrouf A (2007) Antibiotic resistance genes detected by multiplex PCR assays in Staphylococcus epidermidis strains isolated from dialysis service. Jpn J Infect Dis 60: 183-187.

33. Helmy MM, Allam AA, Mohamed MS, Amer A, and Abd Aldaem A (2006) Slime forming Staphylococcus epidermidis isolated from orthopedic prosthesis infections and its sensitivity to antibiotics. EJMM 15: 205-213.

\section{Corresponding Author}

Rehab Mahmoud Abd El-Baky

Address: 56, Adnan El-Malky street, Ard sultan, El-Minia, Egypt.

Mobil: (02)-0123350610.

Email: dr_rehab010@yahoo.com

Conflict of interest: No conflict of interest is declared. 